\title{
Wave Power Resource in Iran for Electrical Power Generation
}

\author{
Jawad Faiz $^{1, *}$, M. Ebrahimi-salari ${ }^{2}$ \\ ${ }^{1}$ Center of Excellence on Applied Electromagnetic Systems, School of Electrical and Computer Engineering \\ University of Tehran \\ ${ }^{2}$ Young Researchers Club, Islamic Azad University, Najafabad Branch, Isfahan, Iran \\ *Corresponding author.Tel: +9821 61114223,Fax:+282188633029, E-mail: jfaiz@ut.ac.ir
}

\begin{abstract}
This paper presents the physics of ocean waves and its governing mathematical equations. The potentials of the Seas in Iran for wave's energy conversion into electrical energy using linear permanent magnet generators are discussed. The characteristics of the Seas and the useable regions for wave energy conversion are recognized. Finally economics of this energy conversion is analyzed.
\end{abstract}

Keywords: Wave Energy, Electrical Power Generation, Iran

\section{Introduction}

Direct-driven linear permanent magnet generator (LPMG) is a wave energy converter which has a simple structure, easy fixing, low volume, high efficiency and capability of converting the calm waves into electrical energy [1-4]. Falnes [5] introduced several theories for direct wave energy conversion systems and studied different forms of buoys for such energy extraction. LPMG consists of a movable and a fixed part. The magnetic field of the generators is provided by permanent magnet fixed on the moving piston. As shown in Fig. 1, the generator is fixed at the bottom of the sea and its piston is connected to a buoy on the sea level by a rope. The waves move the shaft, induce voltage in the armature windings and it is rectified and transmitted to the coasts by underwater cables.

Different techniques for converting wave's energy into electrical energy are categorized into three parts based on the distance from the shore as 1) shoreline, 2) near shore and 3) offshore. The shoreline systems have advantages such as easy fixing and low maintenance and they do not need very deep water or underwater cables; however, their generated power are too low because of low energy of the waves approaching the shore. Therefore, it is sometimes noneconomical to install such system for wave energy conversion. The offshore systems enable to convert more wave's energy due to the stronger waves in the deeper water. LPMGs are considered as offshore devices which must be installed deeper than $15 \mathrm{~m}$ in order to gain an optimal efficiency. The existing wave energy depends directly on the wave height and its time period. One of the most important stages in the design, simulation and analysis of LPMG is the wave characteristic and modeling for the region in which the generator is fixed.

This paper considers the physics of the ocean waves and their stored energy. Characteristics of the seas in Iran are investigated. The attempt is made to recognize the regions in which the use of LPMG is suitable based on the sea depth, distance from shore and waves height. Also these characteristics can be included in the process of the design of LPMG. Finally, economics of the wave energy conversion is studied and compared with other forms of renewable energies.

\section{Ocean Waves Energy}

The total waves energy in the world coasts is estimated to be $10^{6} \mathrm{MW}$ and if only $2 \%$ of this energy is extracted it can supply the total world energy demand [1]. Generally ocean waves are categorized into wind-sea and swell waves. The wind-sea is used for the waves that generated 
by the local winds, and waves move in the direction of these winds. The waves with long period generated in the stormy regions are called swell waves. The swell waves with very low energy losses spread from coast to coast. The typical wave length of swell waves, particularly in deep water, is 100-500 m, while the wind-seas are few meters up to $500 \mathrm{~m}$ depending on the wind velocity. In the installing LPMG in the deep water those waves are taken into account that has the depth larger than a half wave length [5]. In the deep water, the bottom of sea has no noticeable influence on the waves and their effects are ignored. Normally at a specific time, many waves' pulses are generated over offshore in different directions and periods. Wind-sea and swell may present simultaneously. A real ocean wave consists of the waves with different frequencies and directions. The mean stored energy in the unit area of the sea surface is as follows [1-13]:

$$
E=\rho g H_{m 0}^{2} / 16=\rho g \int_{0}^{\infty} S(f) d f
$$

where $\rho=1030 \mathrm{~kg} / \mathrm{m}^{3}$ is the sea water density, $H_{m 0}$ is the water height in the natural case and $g=9.81 \mathrm{~m} / \mathrm{s}^{2}$.This stored energy is equally divided into the kinetic and potential energies. In (1), $S(f)$ is the wave spectrum in $\mathrm{m}^{2} / \mathrm{Hz}$. Integration of $S(f)$ shows the effects of frequencies of different waves upon the waves energy. In practice, (1) is substituted by sum of the limited number of waves frequencies. For sinusoidal waves having amplitude of $0.5 \mathrm{H}(\mathrm{H}$ is the height of the wave, vertical distance between the lowest and highest points of the wave) $H_{m 0}$ is substituted by $H \sqrt{2}$ in (1) to calculate $E$. The approximate natural wave of $S(f)$ is defined using Fourier analysis by measuring the wave at a given time. To obtain the long-term statistics, measurement and analysis are taken every three year. For growth wind seas, the empirical Prison-Moskowitz spectrum agrees well with the practical spectra and calculated as follows:

$$
S(f)=\left(A / f^{5}\right) \exp \left(-B / f^{4}\right)
$$

where $A=B H_{m 0}{ }^{2} / 4=0.0005 m^{2} H z^{4}, B=(5 / 4) f_{P}{ }^{4}=0.74 g^{4} /(2 \pi U)^{4} . f_{P}=1 / T_{P}$ is the peak frequency and $U$ is the mean velocity of the wind at height of $15 \mathrm{~m}$ above the sea level. For a low reaction between the wind and sea level, the use of JONSWAP spectrum is more common; the band width of this spectrum is narrower than that of the Prison-Moskowitz spectrum. The torque of j-order wave moment is $m_{j}=\int_{0}^{\infty} f^{j} S(f) d f$. Therefore, the significant wave may be defined versus 0 -order torque spectrum as $H_{m 0}=4 \sqrt{m_{0}}$. To simplify the investigation it is assumed that the wave is propagated in $\mathrm{x}$ direction. For a sinusoidal wave with frequency $f$, the energy of the wave is transferred with velocity $c_{g}$ (group velocity). The wave power level, defined as transferred energy over every unit width of the propagating front wave, is equal to $J=c_{g} E=c_{g} \rho g H^{2} / 8$. For real sea waves, the level of wave power versus wave spectrum is:

$$
J=\rho g \int_{0}^{\infty} c_{g}(f) S(f) d f=\rho g^{2} m_{-1} / 4 \pi=\rho g^{2} T_{J} H_{m 0}^{2} / 16
$$

Eqn. (1) is true in deep water, where $c_{g}=g T / 4 \pi=g / 4 \pi f$ and energy period as $\mathrm{T}_{\mathrm{J}}=\mathrm{T}_{-1,0}=\mathrm{m}_{-1} / \mathrm{m}_{0}$. The level of the wave power can be estimated by integrating the power density flow: $\mathrm{J}=\int I(z) d z$ in $\mathrm{z}$ direction (direction of water flow). The peak wave power density is as follows: $I(0)=2 \pi \rho g m_{1}=\left(\frac{\pi}{8}\right) \rho g H_{m 0}^{2} / T_{0,1}$ 
under water level $\mathrm{z}=0$, the wave power density has its maximum value and it is more decreased by moving lower sea level. For perfectly growth wind-seas, we have the following based on Prison-Moskowitz spectrum:

$$
I(0)=0.0325 \rho g^{3 / 2} H_{m 0}^{3 / 2}=5 I_{\text {wind }}
$$

where $I_{\text {wind }}$ is the peak wind energy. For a sinusoidal wave in deep water, $H_{m 0}$ is substituted by $H \sqrt{2}, T_{J}$ and $T_{1,0}$ by $T$ in (4) and (5). The power density varies proportional with $\mathrm{z}$. $I(z)=I(0) \exp (2 \mathrm{kz})$ where $k=2 \pi / \lambda$ is the wave number, and $\lambda=g T^{2} / 2 \pi=\left(1.56 \mathrm{~m} / \mathrm{s}^{2}\right) T^{2}$ is the wave length. $96 \%$ of $J$ is calculated from integrating between $z=-\lambda / 4$ and 0 . Decreasing water depth means approaching the wave near shore. In this case wave length reduces uniformly. However, $\mathrm{c}_{\mathrm{g}}$ rises $20 \%$ compared with the deep waters. Value of $c_{g}$ is decreased by reduction of $\mathrm{h}$ and it nearly diminishes when approaches the shore (zero wave energy). In the shoreline, the wave energy is used to overcome the friction between the waves and shore bottom and depth-induced braking force.

In latitude of 40-50 degrees, the average annual wave's power levels in off-shore water are between 30 and $100 \mathrm{~kW} / \mathrm{m}$. The low power level waters are mostly in the north and south. In most equatorial waters, the average wave power level is lower than $20 \mathrm{~kW} / \mathrm{m}$. The offshore wave power levels are between $\mathrm{kW} / \mathrm{m}$ up to $\mathrm{MW} / \mathrm{m}$ (in the case of variable storm). Finally, a general equation for estimation of the stored energy in the real sea waves, propagated in different directions, is as follows:

$$
E=\rho g H_{m 0}^{2} / 16=\rho g \int_{0}^{\infty} \int_{\beta_{1}}^{\beta_{2}} S(f, \beta) d f d \beta
$$

where $S(f, \beta)$ is the oriented energy spectrum, and $\beta$ is the propagation angle in respect to $\mathrm{x}-$ axis. The transferred power density from the waves to a floating cylinder with diameter equal to $1 \mathrm{~m}$ and normal (vertical) path in $\theta$ direction is as follows:

$J_{\theta}=\left(\rho g^{2} / 4 \pi\right) \int_{0}^{\infty} \int_{\beta 1}^{\beta 2} f^{-1} S(f, \beta) \cos (\beta-\theta) d f d \beta$

For sinusoidal waves in deep waters, the transferred power density from the waves to $1 \mathrm{~m}$ diameter floating cylinder and its wave length are as follows;

$J=\rho g^{2} T H^{2} /(32 \pi) \quad W / m$

$J_{\theta}=\left(\rho g^{2} / 4 \pi\right) \int_{0}^{\infty} \int_{\beta 1}^{\beta 2} f^{-1} S(f, \beta) \cos (\beta-\theta) d f d \beta \quad W / m$

\section{Characteristics of Sea Waves in Iran}

\subsection{Persian Gulf}

Persian Gulf is situated between the north attitude of 25 and 32 degrees and between east attitude 49 and 56 degrees. The Persian Gulf area is about $850 \mathrm{~km}^{2}$ which has been connected to the Oman Sea by the Hormoz Channel. The depth of the Persian Gulf increases from northwest to south-east and reaches to $100 \mathrm{~m}$ and lower depth in the Hormoz Channel. The water depth in Khozestan and Saudi-Arabia shores is very low and at most $10 \mathrm{~m}$ along tens $\mathrm{km}$ of the shores; while in the east of Khozestan, particularly in Kangan Port up to Gheshm Island, 
the average depth is larger. The average depth of the Persian Gulf is basically about 40 to 50 $\mathrm{m}$ and is lower toward to the shores. There are sometimes high depth in the shores (around 40 $\mathrm{m})$ which are small and a limited number of cavities and they cannot be considered as the real depth of the shore. The common depth in the shores is 18 to $29 \mathrm{~m}$. So the Persian Gulf shores are generally flat and at the same time the deeper shores are in the north of the Persian Gulf $[14,15]$.

Fig. 2 exhibits the Persian Gulf map [16]. It shows that the depth of water over tens km of the shore is not larger than $10 \mathrm{~m}$, this is the reason that most parts are not suitable for installing LPMGs. Because, the regions deeper than $15 \mathrm{~m}$ are very far from the shore and this increases the energy transmitting cost to shore. Also due to the limitation of deep areas in Persian Gulf, most of these areas are used as path for passing the large ships. However, in Asaloyeh, Gavbandi and particularly Hormoz Channel the deep regions are closer to the shore and suitable for installing the generators.

Fig. 3 shows the waves height in the Persian Gulf during 100-year period [17]. The stored energy in the waves has a direct relationship with the wave height. As indicated in Fig. 3, the waves height in areas close to the shores of Iran are higher than other points. According to Fig. 3, the west regions of the Persian Gulf up to the Gheshm Island and particularly Hormoz Channel with wave height of 4.5-5 m, up to $5 \mathrm{~km}$ of the shore are suitable regions for installing LPMGs. Considering sinusoidal waves with period of $4 \mathrm{~s}$, the peak energy of the waves in these regions is estimated by (4), which is between 79.74 and $98.44 \mathrm{~kW} / \mathrm{m}$.

\subsection{Oman Sea}

Oman Sea is part of the Indian Ocean and is only open Sea of Iran. Persian Gulf in connected to Oman Sea via Hormoz Channel. The tropic of cancer passes the north of Oman Sea. It is one of the warmest seas on the south-west of Asia. The minimum water temperature in August is 33 and minimum in January 20 degrees. The area of the Oman Sea is 903 square $\mathrm{km}$. This Sea is deeper than Persian Gulf particularly in the shores of Iran. Its depth around Chabahar Port is around $3380 \mathrm{~m}$. There are many notches in the Oman Sea forming small Gulfs locally such as Chabahar Gulf and Govatr Gulf. However, most of these small Gulfs have low depth and they are not useable for large ships because their shores are sandy For this purpose, it is necessary to establish docks $[14,16]$. Fig. 4 exhibits the map of Oman Sea [17]; which includes the depth of the Sea in different regions. Fig. 5 shows the peak height of the wave in the Oman Sea over 100-year

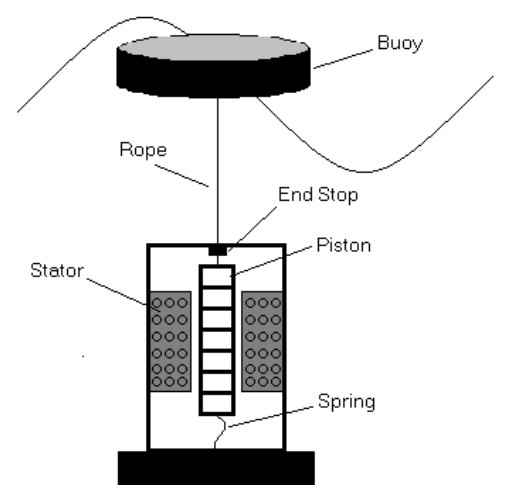

Fig. 1. Direct wave energy

conversion system

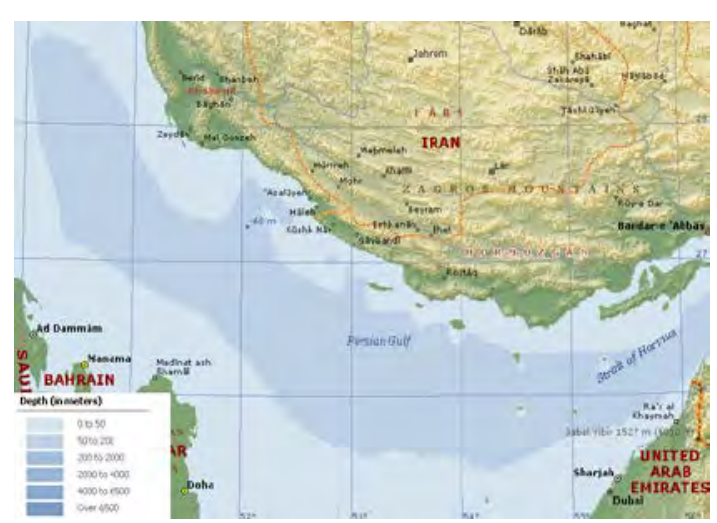

Fig. 2. Map of Persian Gulf 

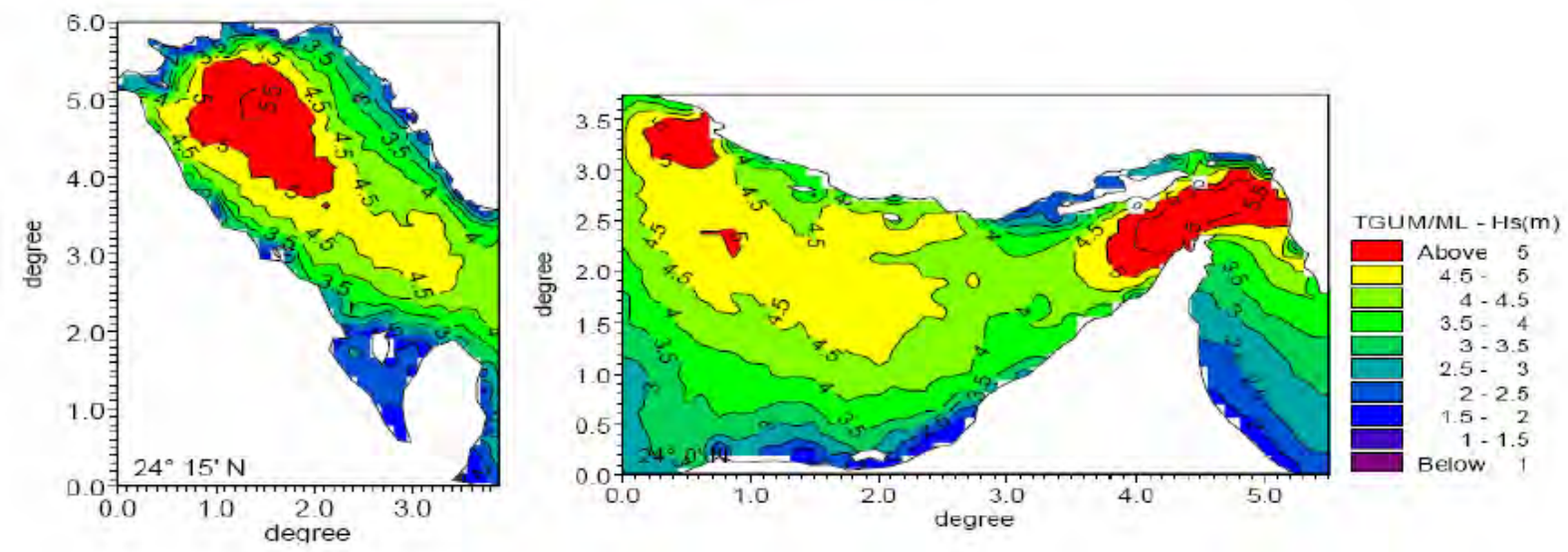

Fig. 3. Peak waves energy in Persian Gulf in 100-year period [17].

period [17]. In this Sea the deep areas (deeper than $15 \mathrm{~m}$ ) are closer to the shores. However, the peak height of the waves is lower than that of the Persian Gulf and is between 3 and $4 \mathrm{~m}$.

Considering sinusoidal waves with period of $4 \mathrm{~s}$, the peak energy of the waves in these regions based on (9) is estimated between 35.44 and $63 \mathrm{~kW} / \mathrm{m}$. The advantages of deeper Sea close the shores are that the cost of transmitting the generated electrical power to the shores is lower. Finally most of the shores particularly Chabahar shores are suitable to install LPMGs.

\subsection{Caspian Sea}

Caspian Sea in the north of Iran has $424000 \mathrm{~km}^{2}$ area and is the largest lake of the earth and that is why it is called the Sea. This is the largest remaining portion of the ancient Sea of Tetis which extended from the North Pole to Indian Ocean in the $1^{\text {st }}$ to $3^{\text {rd }}$ geology ancient time. The depth of the Caspian Sea in the north region is very low and about its $4 / 5$ area has lower than $10 \mathrm{~m}$ depth. The peak depth of this Sea in the north is $15 \mathrm{~m}$ and in the south is $1000 \mathrm{~m}$. The average depth of this Sea is $325 \mathrm{~m}$. Basically, Caspian Sea is not a calm Sea. It is in the path of the air flow in many days of the year and is wavy. The waves created by the north which extended from the North Pole to Indian Ocean in the $1^{\text {st }}$ to $3^{\text {rd }}$ geology ancient time.

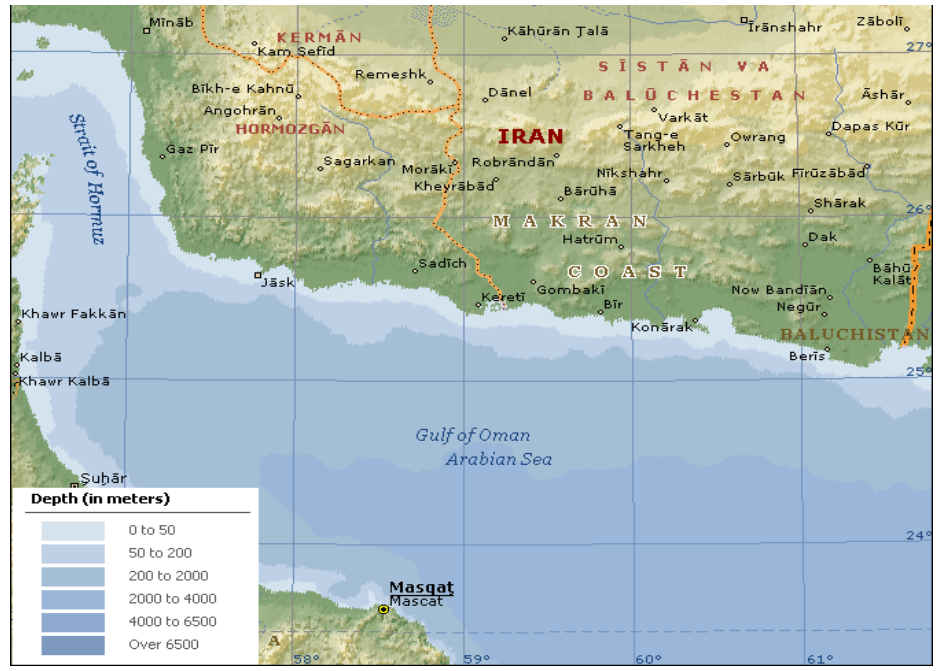

Fig. 4. Map of Oman Sea [16]. 


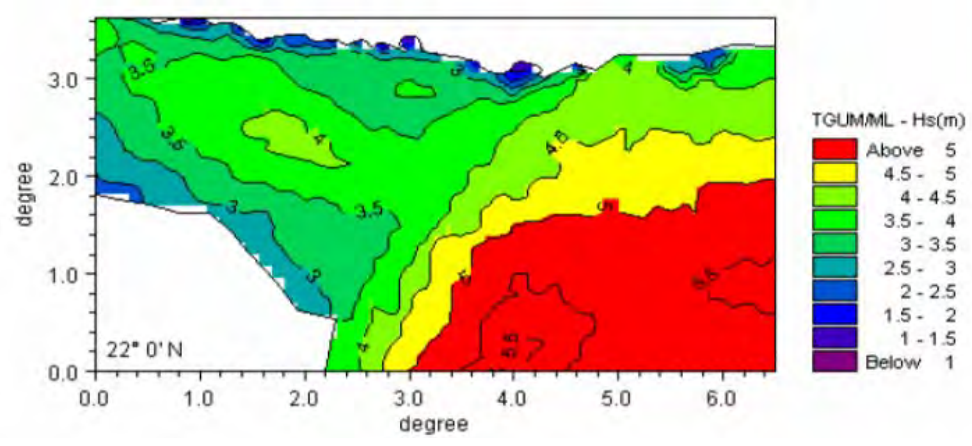

Fig. 5. Peak height of the wave in the Oman Sea over 100 years period [17]

The depth of the Caspian Sea in the north region is very low and about its $4 / 5$ area has lower than $10 \mathrm{~m}$ depth. The peak depth of this Sea in the north is $15 \mathrm{~m}$ and in the south is 1000 $\mathrm{m}$. The average depth of this Sea is $325 \mathrm{~m}$. Basically, Caspian Sea is not a calm Sea. It is in the path of the air flow in many days of the year and is wavy. The waves created by the north winds often have $25 \mathrm{~m} / \mathrm{s}$ velocity, 11 to $12 \mathrm{~m}$ height and $200 \mathrm{~m}$ wave length. The major part of these waves is formed by these waves. The frequency of the waves is larger in the west and middle parts and therefore these parts are more non-calm compared with other parts $[18,19]$. This wavy Sea has large potential for waves energy conversion. Fig. 6 and Fig. 7 show the Caspian Sea map and the peak height of the waves in 100-year period respectively [16, 17]. Referring to Fig. 7, the height of the waves particularly close to the shores in Iran is very large which indicates the large potential of this Sea for converting the waves energy into electrical energy. In Caspian Sea the regions with high wave height and depth larger than $15 \mathrm{~m}$ are close to the shore and their distances to the shore are less than $5 \mathrm{~km}$. This feature reduces the cost of electrical energy transmission. Considering sinusoidal waves with period of $5 \mathrm{~s}$, the peak energy of the waves in these regions is estimated between 123 and $315 \mathrm{~W} / \mathrm{m}$ by (9).

\section{IV. Economics of Wave Energy Conversion}

To estimate the economics of the available renewable energy conversion the following merit index has been defined:

$\alpha=\frac{P_{\text {ave }}}{P_{r}}=\frac{W}{8760 P_{r}}$

where $\alpha$ is the merit index, $P_{r}$ is the rated power, $P_{\text {ave }}$ is the mean developed power in $\mathrm{kW}, W$

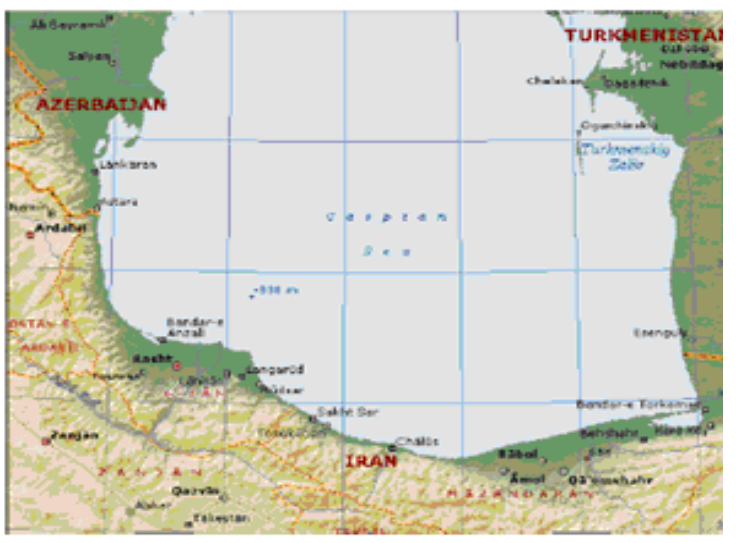

Fig. 6. Caspian Sea map

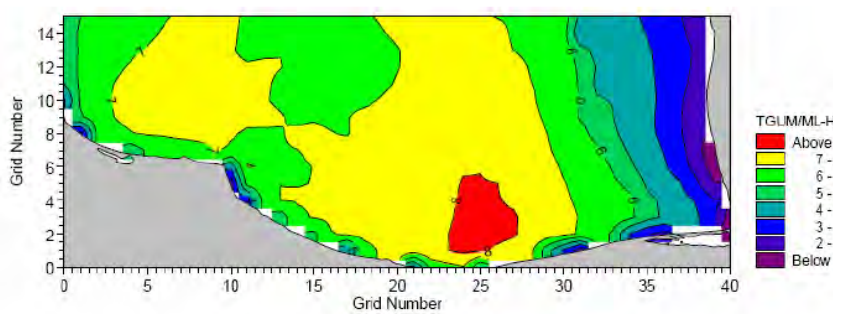

Fig. 7. Peak height of the wave in the south of 


\section{Caspian Sea over 100 years period}

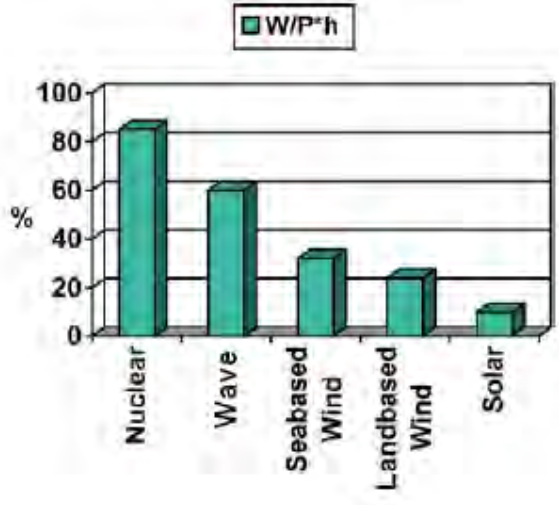

Fig. 8. Merit index for different types of renewable energies [20].

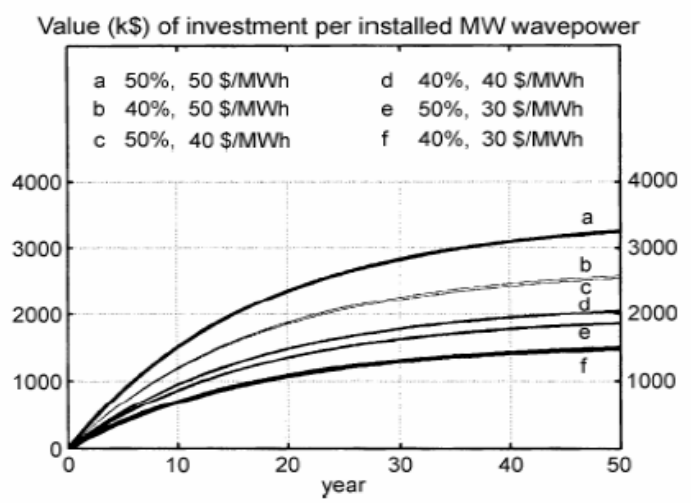

Fig. 9. Value of investment per installed $M W$ wave power for different values of the utility factor and electricity price [20]

is the generated energy over one year in $k W h$ and 8760 is total hours of the year [20]. Fig. 8 shows the merit index for different renewable energy systems. It shows that the waves energy has $60 \%$ merit index and places in the second rank after the nuclear energy. The wave energy is superior to the wind energy from generation time period and generation level points of view. The wave's energy is damped very calmer than that of the wind energy. Also the peak power density of wave under the sea level is 5 times of $I_{\text {wind }}=\left(\rho_{\text {air }} / 2\right) U^{3}$ at $19.5 \mathrm{~m}$ above the Sea level. For wave energy density of $3.2 \mathrm{~kW} / \mathrm{m}^{2}$ and the mean wind velocity of $U=10 \mathrm{~m} / \mathrm{s}$, the wind power density at $19.5 \mathrm{~m}$ above the Sea level is $0.6 \mathrm{~kW} / \mathrm{m}^{2}$ [14]. Fig. 9 shows that the investment for converting the waves energy into electrical energy is 40-50 \$/MWh [20] where $3 \$ / \mathrm{MWh}$ is for the maintenance. Of course direct conversion systems have not been included in this table. If direct conversion system is used a lower investment is required.

\section{Conclusion}

Physics of Seas waves and their governing equations were studied and then conditions of these Seas for wave's energy conversion into electrical energy were investigated. Persian Gulf is not suitable to install LPMGs due to its very low depth and its deep regions are far from the shore. The Oman Sea is deep and the deep areas are close to the shores and it is capable to generate electrical energy from the wave's energy using LPMGs. The Caspian Sea is wavy due to the path of the air flows in many days of the year and the height of the waves approaches $12 \mathrm{~m}$ and its wave length is very long. Also the depth of water in the south and west sides in Iran is high, therefore Caspian Sea has more potential to convert the waves energy into electrical energy using LPMGs. In order to include the characteristics of the Seas in Iran in simulation and design of LPMGs, it is necessary to have data about the wind velocity, average height of annual waves, and average wave length and time period of the waves. The mentioned data are required to use equations in section 2 of the paper and estimate the power level of these waves and design the generator suitable for this power level.

\section{References}

[1] K. Rhinefrank, et. al., Novel ocean energy permanent magnet linear generator buoy, Journal of Renewable Energy, vol. 31, 2006, pp. 1279-1298. 
[2] Y. Masuda, An experience of wave power generator through tests and improvement, IUTAM Symposium on Hydrodynamics of w ave energy devices- Lisbon, Portugal, Springer Verlag, Berlin,1985, pp.1-6.

[3] N.N. Panicker, Power resource potential of ocean surface waves, Workshop of the wave and salinity gradient, Newark, Delaware, USA, 1976, pp. J1-J48.

[4] H. Polinder, M. Scuotto, Wave energy converters and their impact on power system, International Conf. on Future power systems, vol. 18, Nov. 2005, pp.9-11.

[5] J. Falnes, A review of wave-energy extraction, Journal of Marin Structures, vol. 20, no. 4, Oct. 2007, pp. 185-201.

[6] L. J. Duckers, Wave energy; crests and troughs, Renewable Energy, vol. 5, no. 2 , 1994, pp. $1444-1452$.

[7] J. Falnes and J. Lovstedt, Ocean wave energy" Energy Policy, vol. 19, no. 8, 1991, pp. $768-775$.

[8] H. Bernhoff, E. Sjöstedt, and M. Leijon, Wave energy resources in sheltered sea areas: A case study of the Baltic Sea, Renewable Energy, vol. 31, no. 13, 2006, pp. 2164-2170.

[9] D. Ross, Power from the Waves, Oxford University Press, 1995.

[10] I. Glendenning, Ocean wave power, Applied Energy, vol. 3, no. 3, July 1977, pp. $197-$ 222.

[11] T.T. Janssen, J.A. Battjes, A note on w ave energy dissipation over steep beaches, Coastal Engineering, vol. 54, no. 9, Sep. 2007, pp. 711-716.

[12] D. Mollison, Wave climate and the wave power resource, - IUTAM Symposium on Hydrodynamics of wave energy devices- Lisbon, Portugal, Heidelberg: Springer-Verlag, 1986, pp. 133-56.

[13] J. Falnes, Radiation impedance matrix and optimum power absorption for interacting oscillators in surface Waves, Appl. Ocean Res., vol. 2, no. 2, 1980, pp. 75-80.

[14] M.B. Zomorodian, Geomorphology of Iran, Ferdowsi University of Mashad, Press, $3^{\text {rd }}$ Ed., 2007.

[15] A. Faraji, A complete Geography of Iran, Iran Printing and Publishing Publisher, $1^{\text {st }}$ Ed., 1988.

[16] Microsoft Encarta Reference Library Premium 2005, available in www.Encarta.com.

[17] Iran Ports and Ship Organization, Modeling of Waves in Iran, WWW.pso.ir.

[18] L. Mafkham Payan, Caspian Sea, Hedayat Publishers, 1998.

[19] A. Barimani, Mazandaran Sea, University of Tehran Press, 1977.

[20] M. Leijon, H. Bernhoff, M. Berg, and O. Agren, Economical considerations of renewable electric energy production - especially wave energy, Journal of Renewable Energy, vol. 28, no.8, July 2003, pp. 1201-1209. 